\title{
The Prognostic Value of Early Repolarization Pattern for the Ventricular Tachyarrhythmias of Acute Myocardial Infarction Patients: A Meta-Analysis
}

\author{
Shangbo Xu ${ }^{a}$, b Lihua Yang ${ }^{a}$ Danhua Hong ${ }^{a}$ Lan Chen ${ }^{a}$ Xin Wang ${ }^{a}$ \\ a Department of Cardiology, First Affiliated Hospital of Shantou University Medical College, Shantou, China; \\ bShantou University Medical College, Shantou, China
}

\section{Keywords}

Early repolarization - Acute myocardial infarction .

Ventricular tachyarrhythmias · Prognosis

\begin{abstract}
Several studies have indicated that early repolarization (ER) is a risk factor for ventricular tachyarrhythmias (VTAs) in acute myocardial infarction (AMI) patients. The prognostic values of ER detail characteristics except J-point morphology, and inferior leads ER location for VTAs are still unclear. We searched PubMed, Embase, and the Cochrane Library for eligible studies up to March 4, 2019. Studies to investigate the relationship between ER and the incidence of VTAs in AMI patients were extracted. A total of 10 studies with 2,672 participants were included in the analysis. ER significantly predicted the incidence of VTAs (odds ratio [OR] 3.62, 95\% confidence intervals $[\mathrm{Cl}] 2.77-4.73$ ), regardless of the type of AMI. The presence of ER before AMI (OR 5.58, 95\% Cl 3.41 to 9.12) and after AMI (OR 3.02, 95\% Cl 2.19-4.15) increased the risk of VTAs. The prognostic value of ER for VTAs in the long follow-up ( $\geq 30$ days) (OR $2.39,95 \% \mathrm{Cl} 1.59-3.59$ ) fell by half compared to the short follow-up duration ( $<30$ days) (OR 4.97, 95\% Cl 3.48-7.09). Patients with ER displayed a higher
\end{abstract}

risk of developing ventricular fibrillation (VF) (OR 6.94, 95\% CI 3.87-12.43) than those without ER. However, neither Jpoint elevation with $\mathrm{OR}=2.48$ nor lateral leads' ER location with $\mathrm{OR}=3.83$ remarkably increased the risk of VTAs in patients with AMI. ER is significantly associated with increasing risk of VTAs, particularly VF, in AMI patients. This relationship is weaker in the 30-day follow-up and is not reinforced by $\mathrm{J}$ point elevation and lateral leads' ER location.

(C) 2019 S. Karger AG, Basel

\section{Introduction}

The early repolarization (ER) pattern is a common electrocardiogram (ECG) finding that historically has been regarded as a benign phenomenon [1]. However, recent studies have demonstrated that patients with ER are susceptible to ventricular tachyarrhythmias (VTAs) after the onset of acute myocardial infarction (AMI) [211]. A meta-analysis by Zhang et al. [12] in 2015 revealed that the ER pattern is significantly related to VTAs in patients with AMI, especially the notched ER pattern located in inferior leads. However, the authors did not analyze other specific ER characteristics except J-point morphol-

\section{KARGER}

(c) 2019 S. Karger AG, Basel

E-Mail karger@karger.com

www.karger.com/crd
Prof. Xin Wang

Department of Cardiology

First Affiliated Hospital of Shantou University Medical College

57 Changping Road, Shantou, Guangdong (China)

E-Mail xusb2012@163.com 
Fig. 1. Flow chart of the selection proce-

Studies were identified from the databases $(n=476)$

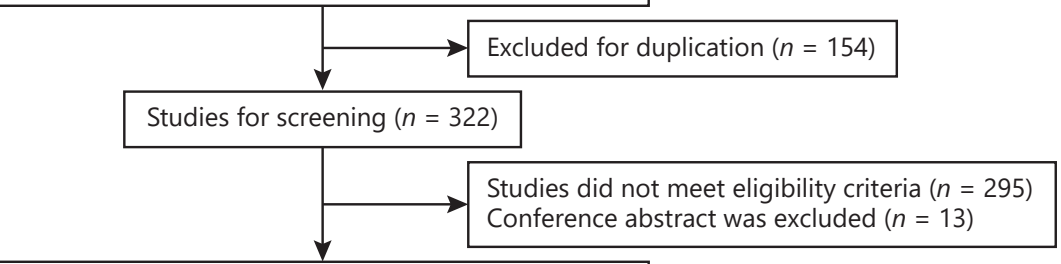

Studies for detailed evaluation ( $n=13$ )

References also checked for potentially eligible studies dure.

Studies included in the final meta-analysis $(n=10)$

ogy (notching or slurring) and inferior leads' ER location due to lack of available data. More importantly, 1 study was missed, and 3 new studies were reported. Therefore, we performed an updated systematic review and metaanalysis to assess whether ER and its detail characteristics were associated with increasing risk of VTAs in patients with AMI.

\section{Methods}

Owing to the inevitable biases of observational studies, we performed this meta-analysis in accordance with the Preferred Reporting Items for Systematic Reviews and Meta-Analyses (PRISMA) statement [13].

Two investigators (S.X. and L.Y.) conducted a systematic search of PubMed, Embase, and the Cochrane Library for eligible studies up to March 4, 2019, using the following keywords: "Osborn wave," Osborn waves," "J-wave," "J-waves," "J wave," “J waves," "early repolarization," "ST elevation myocardial infarction," "non-ST segment elevation myocardial infarction," "acute myocardial infarction," "STEMI," "NSTEMI," “AMI," and "MI."

We included observational studies to investigate the relationship between the ER pattern and the incidence of VTAs in patients with AMI. Two investigators (S.X. and L.Y.) independently screened titles and abstracts and determined eligible articles if they met the following criteria: (1) the study was written in English; (2) the study was a case-control or cohort design; (3) the endpoints were nonsustained ventricular tachycardia (VT), sustained VT, and ventricular fibrillation (VF); (4) the odd ratio (OR) or hazard ratio with 95\% confidence interval (CI) was provided or the data was available to calculate these for evaluating ER in predicting the risk of VTAs in patients with AMI. Conference abstracts were excluded without available full text. Only the latest article was included when studies were carried out on the same population. The disagreements were resolved by discussion with a third investigator (X.W.).
Two investigators (S.X. and L.Y.) independently extracted the information of potentially relevant studies using a prepared checklist which contained the following information: details of the publications (first author's last name, year of publication), study design, study location, sample size, patients' age, follow-up duration, diagnosis of ER before or after AMI onset, endpoint events, number of ST segment elevation myocardial infarctions (STEMI), and number of percutaneous coronary interventions (PCI). Disagreements were resolved by consensus.

All the potential references were imported into the EndNote software. We analyzed data with Review Manager (RevMan version 5.3; Cochrane Collaboration, Oxford, UK). The summary OR and the corresponding 95\% CI were calculated for the value of ER to predict the incidence of VTAs in the patients suffering from AMI (two-tailed $p<0.05$ was considered statistically significant). Relative risk and hazard ratio values in the primary study were considered as OR in all studies, and adjusted OR is prior to unadjusted OR. Heterogeneity in our analysis was evaluated by using $I^{2}$ [14]. If the $I^{2}$ was $<50 \%$, which means low heterogeneity existed, a fixed-effects model was used in the meta-analysis for pooling effect sizes. Otherwise a random-effects model was used. A funnel plot was used to access the publication bias. Sensitivity analyses were conducted by omitting the study if its sample size was less than 100 . We systematically evaluated study quality with the NewcastleOttawa Scale (NOS) [15].

\section{Results}

The flow of the selection is shown in Figure 1. The search strategy yielded 476 potentially relevant studies, of which 154 studies were excluded for duplication. Then, 295 out of the remaining 322 studies were subsequently excluded for not meeting eligibility criteria. At the same time, 13 conference abstracts were excluded. After detailed evaluation, 1 study [16] was excluded because its 
Table 1. Summary of the characteristics of the 10 studies

\begin{tabular}{|c|c|c|c|c|c|c|c|c|c|c|}
\hline Author, year & $\begin{array}{l}\text { Study } \\
\text { design }\end{array}$ & $\begin{array}{l}\text { Study } \\
\text { location }\end{array}$ & $\begin{array}{l}\text { Sample } \\
\text { size }\end{array}$ & $\begin{array}{l}\text { Mean age, } \\
\text { years }\end{array}$ & Follow-up & $\begin{array}{l}\text { Diagnosis of ER } \\
\text { before or after } \\
\text { AMI }\end{array}$ & Endpoint events & $\begin{array}{l}\text { STEMI, } \\
n(\%)\end{array}$ & $\begin{array}{l}\text { PCI, } \\
n(\%)\end{array}$ & $\begin{array}{l}\text { Covariate } \\
\text { adjustment }\end{array}$ \\
\hline $\begin{array}{l}\text { Ali Diab et al. [9], } \\
2015\end{array}$ & $\begin{array}{l}\text { Case- } \\
\text { control }\end{array}$ & Egypt & 102 & 48.4 & $48 \mathrm{~h}$ & Before & $\begin{array}{l}\text { Sustained } \\
\text { VT/VF }\end{array}$ & $72(70.6)$ & $102(100)$ & LVEF QTc and QTd \\
\hline $\begin{array}{l}\text { Kim et al. [5], } \\
2014\end{array}$ & Cohort & Korea & 296 & $61.23 \pm 13.41$ & $48 \mathrm{~h}$ & Before & VF & $193(65.2)$ & $296(100)$ & Unadjusted \\
\hline Naruse et al. [8], 2015 & Cohort & Japan & 281 & $69 \pm 12$ & $48 \mathrm{~h}$ & Before & Sustained VF & $227(81)$ & $281(100)$ & Unadjusted \\
\hline $\begin{array}{l}\text { Patel et al. [2], } \\
2012\end{array}$ & $\begin{array}{l}\text { Case- } \\
\text { control }\end{array}$ & America & 100 & 65.5 & $72 \mathrm{~h}$ & Before & VTAs & $100(100)$ & $100(100)$ & $\begin{array}{l}\text { peak creatine kinase MB } \\
\text { level or LVEF }\end{array}$ \\
\hline Chen et al. [11], 2017 & Cohort & China & 654 & 58.4 & 30 days & After & $\begin{array}{l}\text { Sustained } \\
\text { VT/VF }\end{array}$ & $654(100)$ & $304(46.48)$ & $\begin{array}{l}\text { ACEI, male, LVEF, cTnT, } \\
\text { NT-proBNP, acute PCI, } \\
\text { QTc, HR }\end{array}$ \\
\hline Endo et al. [4], 2014 & Cohort & Japan & 184 & 64.5 & 30 days & After & $\begin{array}{l}\text { Sustained } \\
\text { VT/VF }\end{array}$ & NA & $184(100)$ & Killip grade II-IV \\
\hline Ozcan et al. [6], 2014 & Cohort & Turkey & 521 & 57.2 & 30 days & After & $\begin{array}{l}\text { Sustained } \\
\text { VT/VF }\end{array}$ & $521(100)$ & $269(51.6)$ & Unadjusted \\
\hline $\begin{array}{l}\text { Park et al. [7], } \\
2014\end{array}$ & Cohort & Korea & 266 & $61.6 \pm 12.7$ & $6.7 \pm 4.5$ days & After & VTAs & $266(100)$ & $266(100)$ & $\begin{array}{l}\text { Inferior myocardial infarc- } \\
\text { tion E/E' LVEF }(<45 \%)\end{array}$ \\
\hline Rudic et al. [3], 2012 & $\begin{array}{l}\text { Case- } \\
\text { control }\end{array}$ & Germany & 60 & $61.8 \pm 13.1$ & $\begin{array}{l}\text { During } \\
\text { hospitalization }\end{array}$ & After & VF & $33(55)$ & $60(100)$ & LVEF and QTc \\
\hline $\begin{array}{l}\text { Wu et al. [10], } \\
2019\end{array}$ & $\begin{array}{l}\text { Case- } \\
\text { control }\end{array}$ & $\begin{array}{l}\text { Taiwan } \\
\text { China }\end{array}$ & 208 & $68.9 \pm 15.4$ & $\begin{array}{l}\text { During } \\
\text { hospitalization }\end{array}$ & After & VTAs & $71(34.1)$ & NA & Chronic kidney disease \\
\hline
\end{tabular}

ER, early repolarization; AMI, acute myocardial infarction; STEMI, ST segment elevation myocardial infarction; PCI, percutaneous coronary intervention; VTAs, ventricular tachyarrhythmias; VT, ventricular tachyarrhythmia; VF, ventricular fibrillation; LVEF, left ventricular ejection fraction; QTc, corrected QT interval; QTd, QT dispersion; ACEI, angiotensin-converting enzyme inhibitors; cTnT, cardiac troponin; NTproBNP, N-terminal pro-brain-type natriuretic peptide; HR, heart rate; E/E', peak early diastolic mitral flow and lateral annular velocities; NA, no information available.

Table 2. Detail quality assessment of case-control studies

\begin{tabular}{|c|c|c|c|c|c|c|c|c|c|}
\hline Case-control & $\begin{array}{l}\text { Adequate } \\
\text { definition } \\
\text { of cases }\end{array}$ & $\begin{array}{l}\text { Represen- } \\
\text { tativeness of } \\
\text { the cases }\end{array}$ & $\begin{array}{l}\text { Selection } \\
\text { of controls }\end{array}$ & $\begin{array}{l}\text { Definition } \\
\text { of controls }\end{array}$ & $\begin{array}{l}\text { Comparability of } \\
\text { cases and controls } \\
\text { on the basis of the } \\
\text { design or analysis }\end{array}$ & $\begin{array}{l}\text { Ascertainment } \\
\text { of exposure }\end{array}$ & $\begin{array}{l}\text { Same method } \\
\text { of ascertainment }\end{array}$ & $\begin{array}{l}\text { Non- } \\
\text { response rate }\end{array}$ & Total \\
\hline $\begin{array}{l}\text { Patel et al. [2], } \\
2012\end{array}$ & is & th & & is & 论㑔 & is & is & is & 8 \\
\hline $\begin{array}{l}\text { Wu et al. [10], } \\
2019\end{array}$ & is & 为 & & 㶦 & 论岤 & 访 & is & 岤 & 8 \\
\hline Ali Diab et al. [], 2015 & is & & & 弥 & 论弥 & 弥 & is & & 6 \\
\hline Rudic et al. [3], 2012 & 㑱 & 放 & & 㑱 & 论弥 & 计 & is & 柁 & 8 \\
\hline
\end{tabular}

${ }^{1}$ A maximum of two stars can be allotted in this category. Studies that controlled for age received one star, whereas studies with adjusted analyses received one additional star.

endpoints consisted of VT/VF and sudden death, which would lead to significant contamination of data. Another study [17] was not selected because some patients with VT/VF were calculated repeatedly. Meanwhile, the article by Naruse et al. [18] in 2012 was excluded because it was carried out on the same population as the article published in 2015 [8]. Therefore, 10 studies [2-11] with a total of 2,672 participants were included in the final analysis.

A summary of the characteristics of the 10 studies is presented in Table 1. All of the studies, except the study by
Rudic et al. [3], involved a sample size which was equal to or greater than 100 . The mean age of the participants in the 10 studies ranged from 48.4 to 69 years; 4 studies only recruited the patients after the onset of STEMI, and 7 studies included the patients who absolutely underwent PCI. The adjustments for covariates differed across studies.

Tables 2 and 3 show detail quality assessment of the included studies according to NOS. 9 studies were considered as high quality, and only 1 study with a score of 6 was considered as moderate quality. 
Table 3. Detail quality assessment of cohort studies

\begin{tabular}{|c|c|c|c|c|c|c|c|c|c|}
\hline Cohort & $\begin{array}{l}\text { Representa- } \\
\text { tiveness of } \\
\text { the exposed } \\
\text { cohort }\end{array}$ & $\begin{array}{l}\text { Selection } \\
\text { of the non- } \\
\text { exposed } \\
\text { cohort }\end{array}$ & $\begin{array}{l}\text { Ascertain- } \\
\text { ment of } \\
\text { exposure }\end{array}$ & $\begin{array}{l}\text { Demonstration } \\
\text { that outcome of } \\
\text { interest was not } \\
\text { present at start } \\
\text { of study }\end{array}$ & $\begin{array}{l}\text { Comparability } \\
\text { of cohorts on } \\
\text { the basis of the } \\
\text { design or analysis }{ }^{1}\end{array}$ & $\begin{array}{l}\text { Assess- } \\
\text { ment of } \\
\text { outcome }\end{array}$ & $\begin{array}{l}\text { Was follow- } \\
\text { up long } \\
\text { enough } \\
\text { for outcomes } \\
\text { to occur }\end{array}$ & $\begin{array}{l}\text { Adequacy } \\
\text { of follow- } \\
\text { up of } \\
\text { cohorts }\end{array}$ & Total \\
\hline Naruse et al. [8], 2015 & 论 & 头 & 必 & 岤 & 为 & 岤 & & 岤 & 8 \\
\hline Park et al. [7], 2014 & 拧 & th & 岤 & 为 & 计坛 & 岤 & & 拧 & 8 \\
\hline Chen et al. [11], 2017 & 论 & 象 & 岤 & 功 & 为㑔 & 岤 & 岤 & 论 & 9 \\
\hline Endo et al. [4], 2014 & is & th & 岤 & 诂 & 㶦 & is & 证 & is & 9 \\
\hline Ozcan et al. [6], 2014 & 必 & 放 & 岤 & 岤 & 功 & 岤 & 岤 & 必 & 8 \\
\hline Kim et al. [5], 2014 & 岤 & $\hat{s}$ & is & th & 弥 & th & & 岤 & 7 \\
\hline
\end{tabular}

${ }^{1}$ A maximum of two stars can be allotted in this category. Studies that controlled for age received one star, whereas studies with adjusted analyses received one additional star. ${ }^{2}$ Studies with a follow-up time of 30 days were awarded one star.

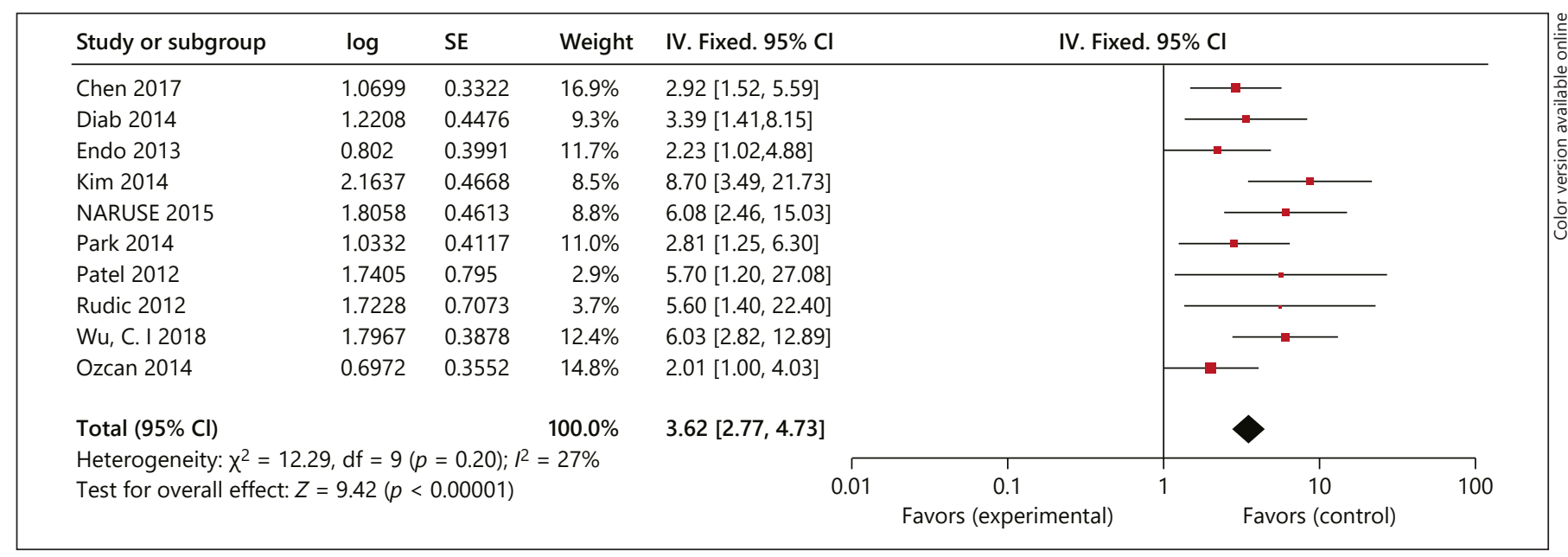

Fig. 2. Forest plot for the association between early repolarization and the risk of ventricular tachyarrhythmias in patients after the onset of acute myocardial infarction.

All studies agreed unanimously with the conclusion that ER increases the risk of VTAs in patients after the onset of AMI. The $I^{2}$ for testing heterogeneity among the individual studies was $27 \%$; therefore, the fixed-effects model was used. The pooled OR of the 10 studies was 3.62 (95\% CI 2.77-4.73; $p<0.00001$ ), which revealed that the risk of VTA was significantly greater in AMI patients with ER compared to controls (Fig. 2).

For minimizing potential heterogeneity, we performed subgroup analyses according to the time of diagnosis of ER (before vs. after infarction), follow-up duration $(<30$ vs. $\geq 30$ days), type of AMI (All patients with STEMI), endpoint events (only VF), J-point elevation, and lateral leads' ER location. Table 4 shows the final results of subgroup analyses. The $I^{2}$ of all the subgroup analyses were less than $25 \%$, except J-point elevation analysis $\left(I^{2}=42 \%\right)$. We found that the presence of ER before AMI (OR 5.58, 95\% CI 3.41-9.12) [2, 5, 8, 9] and after AMI (OR 3.02, 95\% CI 2.19-4.15) $[3,4,6,7,10,11]$ both significantly increased 6- and 3-fold the risk of VTAs, respectively. Overall, 3 studies reported the risk of VTAs in long follow-up duration ( $\geq 30$ days) $[4,6,11]$; the pooled analysis of these studies (OR 2.39, 95\% CI 1.59-3.59) indicated that the risk of VTAs in the long follow-up duration $(\geq 30$ days) fell by half compared to that in the short follow-up duration (<30 days) (OR 4.97, 95\% CI 3.48-7.09) [2, 3, 5, $7-10]$. A total of 4 studies only recruited patients suffering from STEMI $[2,6,7,11]$; the meta-analysis of these studies revealed that patients with ER also had an increased risk of VTAs (OR 2.67, 95\% CI 1.80-3.97) com- 
Table 4. The final results of subgroup analysis

\begin{tabular}{|c|c|c|c|c|c|c|}
\hline \multirow[t]{2}{*}{ Subgroup } & \multirow[t]{2}{*}{ Studies, $n$} & \multicolumn{3}{|c|}{ Meta-analysis } & \multicolumn{2}{|c|}{ Heterogeneity } \\
\hline & & OR & $95 \% \mathrm{CI}$ & $p$ value & $I^{2}$ & $p$ value \\
\hline \multicolumn{7}{|l|}{ Time of diagnosis of ER } \\
\hline Before infarction & 4 & 5.58 & $3.41-9.12$ & $<0.00001$ & $0 \%$ & 0.54 \\
\hline After infarction & 6 & 3.02 & $2.19-4.15$ & $<0.00001$ & $15 \%$ & 0.32 \\
\hline \multicolumn{7}{|l|}{ Follow-up duration } \\
\hline$\geq 30$ days & 3 & 2.39 & $1.59-3.59$ & $<0.00001$ & $0 \%$ & 0.73 \\
\hline$<30$ days & 7 & 4.97 & $3.48-7.09$ & $<0.00001$ & $0 \%$ & 0.6 \\
\hline \multicolumn{7}{|l|}{ All patients with STEMI } \\
\hline Yes & 4 & 2.67 & $1.80-3.97$ & $<0.00001$ & $0 \%$ & 0.65 \\
\hline No & 6 & 4.66 & $3.24-6.69$ & $<0.00001$ & $24 \%$ & 0.26 \\
\hline \multicolumn{7}{|l|}{ Endpoint events } \\
\hline VF & 3 & 6.94 & $3.87-12.43$ & $<0.00001$ & $0 \%$ & 0.82 \\
\hline J-point elevation & 6 & 3.51 & $1.69-7.26$ & 0.0007 & $42 \%$ & 0.13 \\
\hline Lateral leads' ER location & 4 & 3.83 & $1.65-8.89$ & 0.002 & $0 \%$ & 0.74 \\
\hline
\end{tabular}

ER, early repolarization; STEMI, ST segment elevation myocardial infarction; VF, ventricular fibrillation; OR, odds ratio; CI, confidence interval.

pared to those without ER. Overall, 3 studies examined the relationship between ER and the occurrence of VF [3, $5,8]$; our meta-analysis showed that the risk of developing VF was nearly 7 times that without ER (OR 6.94, 95\% CI 3.87-12.43). A total of 6 studies reported the data about J-point elevation [2, 3, 5, 6, 9, 11]; we found that Jpoint elevation was associated with an increased risk of VTAs compared to no J-point elevation (OR 2.48, 95\% CI 1.26-4.86). Finally, 4 studies reported the relationship between lateral leads' ER location and the risk of VTAs [3, 8-10]; we also found that lateral leads' ER location was associated with an increased risk of VTAs (OR 3.83, 95\% CI 1.65-8.89).

On visual inspection of the funnel plot (Fig. 3), the association between ER and VTAs in the patient setting of AMI was asymmetrical at its left middle portion either because of publication bias or a true inexistence of negative studies. We performed sensitivity analysis by removing the study by Rudic et al. [3], because its sample size was less than 100 , and the primary result was not influenced (OR 3.56, 95\% CI 2.71-4.67; $I^{2}=33 \%$; $p=$ $0.16)$.

\section{Discussion}

This meta-analysis identified 10 studies (2,672 participants) in diverse populations and demonstrated that ER on ECG predicts VTAs in patients after the onset of AMI,

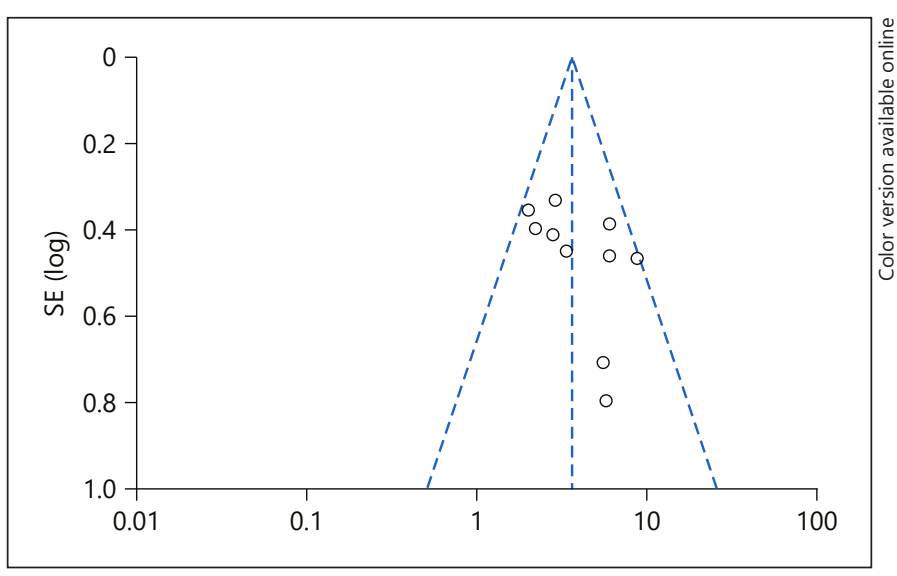

Fig. 3. Funnel plot for the association between early repolarization and ventricular tachyarrhythmias in a patient setting of acute myocardial infarction.

regardless of the type of AMI. Although the ER pattern could be affected by the ongoing AMI, the presence of ER before and after AMI were both significantly associated with increasing risks of VTAs, and the risk of developing VF was more remarkable than in those without ER. However, neither J-point elevation nor lateral leads' ER location with $\mathrm{OR}=3.83$ remarkably increased the risk of VTAs in patients with AMI.

The ER pattern on ECG signals that a distinct action potential notch mediated by transient outward potassium current produces transmural electrical heterogeneity be- 
tween the endocardium and epicardium during early ventricular repolarization. The repolarization dispersion enlarged by this heterogeneity leads to phase 2 reentry capable of initiating VF [19-21]. The prognostic significance of inferior ER location is nearly 3 times greater than the overall result, due to the greater predominance of outward potassium current in the right ventricular epicardium [12]. Our meta-analysis showed that the added risk of lateral leads' ER location was not evident, although the individual leads which constituted lateral leads were slightly different. In other words, inferior ER location has further value in predicting VTAs than lateral leads' ER location.

Similarly, we indicated that J-point elevation did not remarkably increase the risk of VTAs in patients with AMI. However, the amplitudes of J-point elevation were divergent, and ranged from 0.5 to $2.0 \mathrm{mV}$. Up to now, there is still no cut-off amplitude for J-point elevation that could accurately ascertain all patients at risk [22].

Finally, we confirmed that positive predictive values of ER pattern in the long follow-up duration ( $\geq 30$ days) fell by half compared to those in the short follow-up duration ( $<30$ days). A cohort study by Park et al. [7] noticed that ER may sequentially appear and disappear during clinical follow-up. We suppose that the significant differences among different detection window are related to alteration of ER during clinical follow-up. Unfortunately, there is no available study with a little longer detection window (>30 days).

\section{Study Limitations}

Our meta-analysis has several potential limitations. First, we did not extract other factors such as anti-arrhythmic drug use, door-to-balloon, and other underlying diseases which are related with VTAs in the setting of AMI from all of the studies. Second, Adler at al. [23] indicated that J waves followed by a horizontal or descending ST segment, rather than an ascending ST segment, were associated with increased arrhythmic risk. However, on account of the limited available data, we did not analyze ST segment morphology. Third, 3 studies without adjusted analyses were included in this meta-analysis, and the adjustments for covariates differed across studies. Fourth, several studies did not provide detailed and credible data about revascularization strategies such as PCI, thrombolysis, and surgical revascularization. Finally, our present findings are significantly limited by the inevitable selection bias of observational studies, although most studies were considered as high quality.

\section{Conclusion}

Our meta-analysis added ER as a potential prognostic marker for predicting VTAs, especially VF, in patients with AMI. The relationship between ER and the risk of VTAs in patients with AMI was weaker in the long detection window. J-point elevation and lateral leads' ER location did not remarkably increase the risk of VTAs. These may have some applicability in helping to further risk stratify patients that may be candidates for a wearable defibrillator [24]. More studies are required to provide evidence about the prognostic significance of ER detail characteristics in patients with AMI.

\section{Statement of Ethics}

The authors have no ethical conflicts to disclose.

\section{Disclosure Statement}

The authors have no conflicts of interest to declare.

\section{Funding Sources}

No funding was received for this study.

\section{Author Contributions}

Conceptualization and supervision: Danhua Hong and Xin Wang. Data curation, formal analysis, investigation, and methodology: Shangbo $\mathrm{Xu}$ and Lihua Yang. Project administration: Shangbo Xu and Xin Wang. Software: Shangbo Xu. Writing - original draft: Shangbo Xu. Writing - review and editing: Lan Chen and Xin Wang.

References

1 Klatsky AL, Oehm R, Cooper RA, Udaltsova $\mathrm{N}$, Armstrong MA. The early repolarization normal variant electrocardiogram: correlates and consequences. Am J Med. 2003 Aug; 115(3):171-7.

2 Patel RB, Ilkhanoff L, Ng J, Chokshi M, Mouchli A, Chacko SJ, et al. Clinical characteristics and prevalence of early repolarization associated with ventricular arrhythmias following acute ST-elevation myocardial infarction. Am J Cardiol. 2012 Sep;110(5):615-20.

3 Rudic B, Veltmann C, Kuntz E, Behnes M, Elmas E, Konrad T, et al. Early repolarization pattern is associated with ventricular fibrillation in patients with acute myocardial infarction. Heart Rhythm. 2012 Aug;9(8):1295-300. 
4 Endo T, Tomita H, Higuma T, Abe N, Kushibiki M, Saitoh S, et al. Low serum eicosapentaenoic acid level is a risk for ventricular arrhythmia in patients with acute myocardial infarction: a possible link to J-waves. Heart Vessels. 2014 Nov;29(6):847-54.

5 Kim SH, Kim DH, Park SD, Baek YS, Woo SI, Shin $\mathrm{SH}$, et al. The relationship between J wave on the surface electrocardiography and ventricular fibrillation during acute myocardial infarction. J Korean Med Sci. 2014 May; 29(5):685-90.

6 Ozcan KS, Güngör B, Tatlısu MA, Osmonov D, Ekmekçi A, Çalık AN, et al. Presence of early repolarization on admission electrocardiography is associated with long-term mortality and MACE in patients with STEMI undergoing primary percutaneous intervention. J Cardiol. 2014 Sep;64(3):164-70.

7 Park YM, Kang WC, Suh SY, Lee K, Han SH, Shin MS, et al. Early repolarization is associated with atrial and ventricular tachyarrhythmias in patients with acute ST elevation myocardial infarction undergoing primary percutaneous coronary intervention. Int J Cardiol. 2014 Sep;176(2):327-32.

8 Naruse Y, Nogami A, Harimura Y, Ishibashi M, Noguchi Y, Sekiguchi Y, et al. Difference in the clinical characteristics of ventricular fibrillation occurrence in the early phase of an acute myocardial infarction between patients with and without J waves. J Cardiovasc Electrophysiol. 2015 Aug;26(8):872-8.

9 Ali Diab O, Abdel-Hafez Allam RM, Mohamed HG, Mohamed TR, Abel-Hafeez Khalid S. Early Repolarization Pattern Is Associated with Increased Risk of Early Ventricular Arrhythmias during Acute ST Segment Elevation Myocardial Infarction. Ann Noninvasive Electrocardiol. 2015 Sep;20(5):474-80.
10 Wu CI, Chang SL, Lin CY, Vicera JJ, Lin YJ, Lo LW, et al. Clinical significance of J wave in prediction of ventricular arrhythmia in patients with acute myocardial infarction. J Cardiol. 2019 May;73(5):351-357.

11 Chen Q, Zheng M, Liu G, Shi X, Zhang R, Zhou X, Xi Y, Sun J, Zhu C, Chen Y, Cheng J, Yin J: Early Repolarization Pattern Predicts the Increased Risk of Ventricular Arrhythmias in Patients With Acute Anterior ST-Segment Elevation Myocardial Infarction- A Propensity Analysis. Circ J. 2017 Aug;81:1346-53.

12 Zhang Z, Letsas KP, Yang Y, Korantzopoulos P, Li G, Yan GX, et al. Notching early repolarization pattern in inferior leads increases risk of ventricular tachyarrhythmias in patients with acute myocardial infarction: a metaanalysis. Sci Rep. 2015 Nov;5(1):15845.

13 Liberati A, Altman DG, Tetzlaff J, Mulrow C, Gøtzsche PC, Ioannidis JP, et al. The PRISMA statement for reporting systematic reviews and meta-analyses of studies that evaluate health care interventions: explanation and elaboration. Ann Intern Med. 2009 Aug; 151(4):W65-94

14 Higgins JP, Thompson SG, Deeks JJ, Altman DG. Measuring inconsistency in meta-analyses. BMJ. 2003 Sep;327(7414):557-60.

15 Margulis AV, Pladevall M, Riera-Guardia N Varas-Lorenzo C, Hazell L, Berkman ND, et al. Quality assessment of observational studies in a drug-safety systematic review, comparison of two tools: the Newcastle-Ottawa Scale and the RTI item bank. Clin Epidemiol. 2014 Oct;6:359-68.

16 Naruse Y, Tada H, Harimura Y, Ishibashi M, Noguchi Y, Sato A, et al. Early repolarization increases the occurrence of sustained ventricular tachyarrhythmias and sudden death in the chronic phase of an acute myocardial infarction. Circ Arrhythm Electrophysiol. 2014 Aug;7(4):626-32.
17 Nakayama M, Sato M, Kitazawa H, Saito A, Ikeda Y, Fujita S, et al. J-waves in patients with an acute ST-elevation myocardial infarction who underwent successful percutaneous coronary intervention: prevalence, pathogenesis, and clinical implication. Europace. 2013 Jan; 15(1):109-15.

18 Naruse Y, Tada H, Harimura Y, Hayashi M, Noguchi Y, Sato A, et al. Early repolarization is an independent predictor of occurrences of ventricular fibrillation in the very early phase of acute myocardial infarction. Circ Arrhythm Electrophysiol. 2012 Jun;5(3):506-13.

19 Bloch Thomsen PE, Joergensen RM, Kanters JK, Jensen TJ, Haarbo J, Hagemann A, et al. Phase 2 reentry in man. Heart Rhythm. 2005 Aug;2(8):797-803.

20 Gussak I, Antzelevitch C. Early repolarization syndrome: clinical characteristics and possible cellular and ionic mechanisms. J Electrocardiol. 2000 Oct;33(4):299-309.

21 Yan GX, Antzelevitch C. Cellular basis for the electrocardiographic J wave. Circulation. 1996 Jan;93(2):372-9.

22 Patton KK, Ellinor PT, Ezekowitz M, Kowey P, Lubitz SA, Perez M, et al.; American Heart Association Electrocardiography and Arrhythmias Committee of the Council on Clinical Cardiology and Council on Functional Genomics and Translational Biology. Electrocardiographic Early Repolarization: A Scientific Statement From the American Heart Association. Circulation. 2016 Apr;133(15):1520-9.

23 Adler A, Rosso R, Viskin D, Halkin A, Viskin S. What do we know about the "malignant form" of early repolarization? J Am Coll Cardiol. 2013 Sep;62(10):863-8.

24 Sandhu U, Rajyaguru C, Cheung CC, Morin DP, Lee BK. The wearable cardioverter-defibrillator vest: indications and ongoing questions. Prog Cardiovasc Dis. 2019 May;S0033-0620(19)30080-5. 